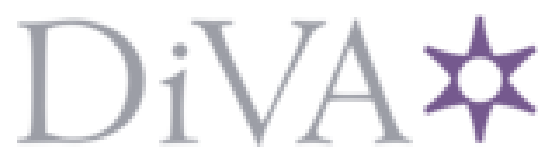

http://www.diva-portal.org

This is the published version of a paper published in Philosophical Studies.

Citation for the original published paper (version of record):

Tännsjö, T. (2015)

A realist and internalist response to one of Mackie's arguments from queerness.

Philosophical Studies, 172(2): 347-357

http://dx.doi.org/10.1007/s1 1098-014-0306-z

Access to the published version may require subscription.

N.B. When citing this work, cite the original published paper.

Permanent link to this version:

http://urn.kb.se/resolve?urn=urn:nbn:se:su:diva- 101367 


\title{
A realist and internalist response to one of Mackie's arguments from queerness
}

\author{
Torbjörn Tännsjö
}

Published online: 2 March 2014

(C) Springer Science+Business Media Dordrecht 2014

\begin{abstract}
If there is such a thing as objectively existing prescriptivity, as the moral realist claims, then we can also explain why-and we need not deny that-strong (conceptual) internalism is true. Strong conceptual internalism is true, not because of any belief in any magnetic force thought to be inherent in moral properties themselves, as Mackie argued, but because we do not allow that anyone has (in the practical sense) 'accepted' a normative claim, unless she is prepared to some extent to act on it (to see to it that it is satisfied).
\end{abstract}

Keywords Internalism - Satisfaction-conditions of norms · Normativity · Mackie · Tresan - Garner and Olson

\section{Introduction}

John Mackie famously argued that, when we make moral judgements, not only do we ascribe an objective property to the actions we are passing moral judgements upon, but we also attribute to it a property which is inherently prescriptive. He thought that we think, when we say of a certain action that it is right, not only that it has a certain objective property (rightness) but also that this property has the property in its turn to motivate us to act, at least when we are acquainted with it. Moral properties, then, have 'intrinsic to-be-pursuedness' built into them. But such a property would be very queer indeed, he claims. And he concludes from the queerness of this property that it cannot be part of the fabric of the universe. It is rather something that we (incorrectly) project on the world. This is one-but only one-aspect of his argument from queerness. His argument from queerness is one of two arguments for moral nihilism. The other one is his argument from relativity.

T. Tännsjö (ه)

Stockholm University, Stockholm, Sweden e-mail: torbjorn.tannsjo@philosophy.su.se 
Here I am only concerned with his argument from queerness and, in particular, his discussion about prescriptivity. This is how he states the premise of his general argument from queerness:

If there were objective values, then they would be entities or qualities or relations of a very strange sort, utterly different from anything else in the universe. $^{1}$

What, then, would be strange (queer) about them? This is how he puts the argument from the putative queerness of prescriptivity. He explains, with reference to Plato's idea of the Form of the Good, what this kind prescriptivity, or intrinsic to-bepursuedness, would amount to:

The Form of the Good is such that knowledge of it provides the knower with both a direction and an overriding motive; something's being good both tells the person who knows this to pursue it and makes him pursue it. $^{2}$

A fairly standard answer from non-naturalist moral realists to this objection from prescriptive queerness goes as follows. Mackie is right when he insists that a property, acting at a distance, magnetically as it were, providing us with an overriding motive would be a very strange (queer) property. However, he is wrong when he believes that we attribute such a property to an action when we claim that it is right. We do attribute an objective property, they claim. However, we do not attribute any inherently motivating property. But is not this a counter-intuitive response? Is Mackie not right in his insistence that there is a close connection between moral properties, and motivation?

$\mathrm{He}$ is, or, at least, he is close to the mark. Mackie is wrong when he believes that we take moral properties as such to motivate us to act, when we learn about them, but our moral beliefs have such a tendency. Even when we hold false moral beliefs we are somewhat motivated to act on them, one could add. In this most nonnaturalist moral realists concur. And here is their standard explanation of our 'internalist' intuition to the effect that there is a close connection between moral belief (rather than moral properties as such) and motivation. It is certainly true that most people, when they believe that an action ought to be done, have some incentive to perform this action. But this does not mean that the property of obligatoriness $a s$ such has any inherent magnetic force attached to it, which is released when we become acquainted with it. It is because most people care about doing their duty that they are somewhat inclined to do a certain action, once they acknowledge that it is obligatory.

This motivation could be explained along the following lines: Given a nonnaturalist objectivist semantic account of normative language, normative judgements, such as most typically the expression of obligations, have, not only truthvalues, but satisfaction-values as well. The proposition that I ought to do F can be satisfied or not satisfied. It is satisfied, if I do F, and it is not satisfied, if I don't. And

\footnotetext{
1 Mackie (1977, p. 38).

2 Ibid. (p. 40), my italics.
} 
we take an interest in these satisfaction-values. These satisfaction-values explain what it means for norms to be 'prescriptive', or what it means for it to give us 'direction'. And our general interest in having them satisfied explains our motivation in a particular case. The same goes for judgements to the effect that it is wrong to F. This judgement is satisfied if we do not F. Our normative vocabulary contains also judgements to the effect that it is all right to $F$ ( $F$ is right). This judgement is satisfied regardless of whether we do F or not. Hence, we take no special practical interest in it. In the sequel I will just discuss norms proper, i.e. judgements to the effect that we ought to $F$ or to the effect that it is wrong to $F$, having both necessary and sufficient satisfaction-conditions.

The internalist may object, however, and correctly so I believe, and Mackie himself would have been well advised to concur, ${ }^{3}$ that the empirical fact that most people care to have their favoured norms satisfied does not fully explain our internalist intuition to the effect that, necessarily, if you believe that you ought to do $\mathrm{F}$, you have at least some motive to do F. However, given the notion of satisfaction of norms, we can indeed explain this intuition, without having recourse to the idea that normative properties are inherently motivating. This is how we can do it.

\section{A new internalism}

Let us return to the satisfaction values and truth-values of a norm and consider them more in detail. We then see that, after all, there is a sense in which, necessarily, if we hold a normative view, we are inclined to act on it. This is, as I will show, a conceptual truth.

The moral non-naturalist realist believes that when we pass moral (normative) judgements we express propositions capable of being true or false and believes also that there are true moral propositions, i.e. moral (normative) facts, existing independently of our conceptualisation. How does this view square with internalism, the view that, necessarily, if someone believes an action to be wrong, then this person has at least some motive to avoid performing the action? Moral realism, in a nonnaturalist version often defended in these days, ${ }^{4}$ is consistent with internalism. The (best) explanation is as follows. Internalism is a conceptual truth, explained by the nature of moral beliefs in combination with how sometimes we use the word 'accept'. As we will see, my account is inconsistent with naturalism, both in a conceptual and an ontological form. I see this as a strong aspect of my account. I can explain what is lost in the transaction, when normative terms or properties are reduced to, or identified with, non-moral terms, to wit, their normativity (their satisfaction-conditions).

On an objectivist and non-naturalist understanding of moral language the content of beliefs such as the belief that it is wrong for $\mathrm{P}$ at $\mathrm{t}$ to $\mathrm{F}$ has both truth-values and satisfaction-values, then. The content of this belief, which is a moral proposition to the effect that it is wrong for $\mathrm{P}$ at $\mathrm{t}$ to $\mathrm{F}$, is true if and only if it is wrong for $\mathrm{P}$ at $\mathrm{t}$ to $\mathrm{F}$; the

\footnotetext{
3 See Dreier (2010, p. 82), for an argument to the extent that Mackie 'mislocated' the problem to the object of moral beliefs rather than to the beliefs themselves.

${ }^{4}$ For example by Parfit (2011) and Tännsjö (2010).
} 
content of this belief is satisfied by $\mathrm{P}$ at $\mathrm{t}$ if and only if, at $\mathrm{t}, \mathrm{P}$ does not $\mathrm{F}$. And the moral principle that we ought to maximise the sum total of happiness in the universe is true, if and only if we ought to maximise the sum total of happiness in the universe. It is satisfied if and only if every action in the universe does maximise the sum total of happiness. The case with moral rightness (permissions), as indicated above, is a bit different. The content of my belief that it is right for $\mathrm{P}$ at $\mathrm{t}$ to $\mathrm{F}$ is satisfied if $\mathrm{P}$ does $\mathrm{F}$ at t. This is a sufficient criterion. There is no corresponding necessary condition. This is part of the explanation behind the fact that beliefs in actions being right do not connect in any close manner to motivation. Yet, when there are some alternatives open to an agent that are each all right for her to perform, then it is also true of the alternatives outside the set of these permissible alternatives, that they are wrong. And here we meet with both sufficient and necessary satisfaction-conditions.

If we have objective moral beliefs (in objective moral propositions), then we are not said to 'accept' these propositions unless we are to some extent behaving in certain manners. If I believe that it is wrong to F, then I do not also believe that it is all right to $\mathrm{F}$, for example. If I believe that it is wrong to $\mathrm{F}$, then $\mathrm{I}$ am prepared to 'conditionalise' on this belief. This is constitutive of my having the belief in the first place. This is no different from my 'having' ordinary non-moral beliefs. And, in a sense, we may say that I do 'have' moral beliefs, if I just conform to this (regular) behavioural pattern of having beliefs in general in my dealings with moral propositions. We may then say that I 'accept' some moral propositions. We may speak of this kind of acceptance or belief as theoretical.

However, since moral propositions, on the objectivist and non-naturalist understanding of moral language, have not only truth-values but also satisfactionvalues, there exists also another way in which we can accept them. The term 'accept' is indeed ambiguous when applied to our attitude to moral propositions. So we had better disambiguate here. In one sense, my conforming to standard behavioural patterns connected with belief in general are sufficient for saying that I have accepted a certain moral proposition. However, since the moral proposition (at least if it is normative in character) has satisfaction-values as well, there is a sense in which I have not really 'accepted' it unless I am not only prepared to conditionalise on it in my theoretical moral thinking; I must also to be somewhat motivated towards satisfying its demands. This is how we (at least most of us, at least most of the time $)^{5}$ tend to speak of people 'accepting' moral propositions, or 'having' moral beliefs. So the internalist intuition that it is impossible to accept that it is wrong to F, and yet not be in the least motivated not to $\mathrm{F}$, is correct.

\section{Tresan's related notion of internalism}

My view here defended may seem reminiscent of a position defended by Jonathan Tresan. It is different however, and it is simpler as well as more

\footnotetext{
5 There are philosophers who have reported that they have no such internalist intuition; this may be true of them, and they may use the term 'accept' differently from how most of us do. Generalizations in the philosophy of language rarely come entirely without exceptions.
} 
general. ${ }^{6}$ According to Tresan, we have a concept of a moral judgement such that we do not count a judgement as moral unless it involves motivation (Tresan 2006, 2009). My view here does not rely on any special notion of a moral judgement, however. It relies on our understanding of what it means to accept a normative proposition. If there are other genuine norms than moral ones (such as epistemic norms, for example), they are covered as well by my explanation. Any proposition with satisfaction-values can be 'accepted' in the relevant practical sense.

It may seem that my view is not so different from Tresan's after all. My postulated connection between acceptance and motivation doesn't just have to do with the meaning of 'acceptance'. For it is only when the term 'acceptance' is coupled with a normative proposition that we have the postulated necessary connection. Isn't that in effect to say what Tresan says, that it is only when the relevant content is accompanied by the right sort of attitude that we call the attitude a moral belief? ${ }^{7}$

But there is a clear difference. On my account the notion of morality plays no role whatever. Whether I have accepted the norm in question has nothing to do with how we classify my acceptance, as moral or as non-moral.

Moreover, and most importantly, according to Tresan, the necessity in, necessarily, if a person accepts that she is obligated to $\mathrm{F}$, she is motivated to $\mathrm{F}$, is, as he puts it, de dicto. It has nothing to do with the content of the moral judgement as such. If we accept Tresan's terminology, we may say that my account is at least partly de re. It explains the necessity with reference to the content of norms, i.e. to the fact that they have satisfaction conditions. And it seems clear to me that the internalist intuition that should be explained is indeed de re.

It might be objected, however, that my kind of internalism only applies to norms, i.e. to moral judgements having satisfaction-values. What are we to say of other moral judgements, such as value judgements? Well, on some 'buck-passing' accounts value judgements are normative judgements in disguise. If this is true, they too are captured by my analysis. On other counts there are value judgements that cannot be reduced to normative claims. They may still have normative conceptual implications. Or, as Mackie puts it, the main ethical uses of value terms may 'refer to supposed intrinsic requirements' (Mackie 1977, p. 63). If they make such references, or have such implications, they are covered by my analysis. If the uses are such that they imply no normative claims whatever, then they are not covered by my analysis. But this is as it should be, I submit. We should not expect that value judgements having no normative conceptual implications connect in this close manner to motivation. Regardless of whether these value judgements belong to 'morality', somehow defined, or not, it is not to be expected that internalism is true of them. So it is a problem for Tresan that if they exist they are covered by his analysis and a strong aspect of my analysis that they if they exist they are not covered by it.

\footnotetext{
6 To my knowledge, my view has not been stated by anyone before me, even if I believe that it must have occurred to many who have thought about the problem. It is not mentioned in Björklund et al. (2011), where Tresan's related view is discussed.

7 I owe this objection to an anonymous reviewer.
} 
My claim is that my analysis is also in a sense more general than Tresan's. The idea of a practical acceptance does not only cover norms but imperatives as well, since imperatives, too, have satisfaction-conditions. You can satisfy 'Shut the door!' by shutting the door. But no one would speak of 'Shut the door!' as a moral claim. Of course, since imperatives have no truth-conditions, they can only be accepted in the practical manner. And there are ordinary factual propositions, such as the proposition that snow is white, which can only be accepted in the theoretical manner. According to normative realism in it non-naturalist version, however, norms have both truth-conditions and satisfaction-conditions. That's why they can be accepted in both a theoretical and a practical manner.

My analysis generalises also to cases where we meet with categorical normative facts that are socially constructed. Such facts are objective in a weak sense. They are objective in the sense that we may be wrong about them. They are not objective in a strong sense, however. They obtain only because we act and judge in a certain manner. It may be natural for example to think of rules of etiquette in this manner. ${ }^{8}$ It is wrong, categorically, to put your elbows on the table when eating. The requirement not to put your elbows on the table when eating can be accepted in both a theoretical and a practical sense. However, because it is an objective fact only in the weak sense, because it does not obtain independently of how we act and judge our actions, it seems to lack what Mackie calls 'authority'. I suppose that, when I feel no inclination to abide by such a requirement, I also tend to reject it in the theoretical sense, and turn to a different understanding of it: 'According to etiquette, you are not allowed to put your elbows on the table when eating', I will think. And this is a description with no satisfaction-conditions.

Furthermore, if moral notions and properties can be reduced to non-moral notions or properties, my account does not capture them. If some kind of naturalistic analysis of moral language or moral facts had been correct, my analysis would have failed. As noted at the beginning of this paper, I see this as a strong aspect of my view. My view can explain what is more exactly that is lost in the reduction of the normative to something non-normative, to wit, the satisfaction conditions. This is just another way of saying that what is typically normative is lost.

It is finally of note that if my account is correct we can explain why a person who claims that it is obligatory to F contextually seems to imply that he has some motivation to F; this has to do with a very general feature; when we assert that $\mathrm{p}$, then we also contextually imply that we believe that (accept that) $\mathrm{p}$. This is true not only for ordinary theoretical acceptance, but for practical acceptance of norms as well. For a discussion on this theme, see Copp (2009).

\section{Is the notion of prescriptivity queer as such?}

When I read Mackie's reference to Plato above I read him as saying: the Form of the Good is such that knowledge of it provides the knower with both a direction (which

8 Tännsjö (2007). 
is not as such queer) and an overriding motive (which is indeed queer). Could one not read him differently: the Form of the Good is such that knowledge of it provides the knower with both a direction (which is in itself queer) and an overriding motive (which is also queer)? I don't think the latter interpretation is correct and it is certainly not a charitable one. This, however, is how he is often understood in these days; it originated with Richard Garner, who wrote:

It is hard to believe in objective prescriptivity because it is hard to make sense of a demand without a demander, and hard to find a place for demands or demanders apart from human interests and conventions. We know what it is for our friends, our job, and our projects to make demands on us, but we do not know what it is for reality to do so. ${ }^{9}$

It would spell problem for my kind of internalism, if the very notion of prescripitivity, i.e. of a norm giving direction, or a requirement, in abstraction from anyone making it, were queer. But is it?

It is true that Mackie did not think that genuine normative requirements exist in the world. That there are no such genuine normative requirements is the thesis he wants to establish with his argument from queerness. But how could Mackie find genuine norms or requirements as such queer? He must believe they are queer, if he wants to state an argument from queerness to moral nihilism or anti-realism (these are not the words Mackie himself uses for his metaphysical denial that there are objective moral properties actually instantiated, but the terms are to the point and they have been common in contemporary discussion about his view). Is Garner right when he insists that it is 'hard to make sense of a demand without a demander'?

I think not. In order to do so we must only be able to tell what demand is made, on a certain occasion, by someone making a demand on us. We can abstract the demand from the one making it in the same way that we can abstract a proposition from a person expressing it (when stating a fact). Norms, genuine requirements, giving you direction, aren't in themselves queer. We can think of them, in abstraction from anyone issuing them, and ponder, for example, their logical relations. Emotivists, of course, deny this but their denial flies in the face of moral phenomenology, and it is a strong aspect of Mackie's objectivist view of moral language that he need not resort to a denial of the existence of moral propositions. We meet with them, and we identify them with reference to both their truthconditions and their satisfaction-conditions. But, if so, Mackie's argument cannot be that norms are so queer in this regard that they cannot be part of the world. And if they are part of the world, then we really have obligations. The fact that they are real also explains why they seem, in a sense, unavoidable to us. The fact that they are real grants them a kind of authority in their own right, regardless of our attitudes.

This does not mean, however, that according to moral realism, reality makes demands on us, in a way similar to how we make demands on one another. This is a

\footnotetext{
9 Garner (1990, p. 143).
} 
mischaracterisation - a caricature, as it were - of moral realism on the part of Garner. If this were a correct characterization of moral realism, if moral realism implied the claim that reality 'spoke' to us, then it would indeed be queer.

I suppose that when Garner in his caricature assumes that the moral (nonnaturalist) realist believes that nature makes demands on us, this is because he thinks that there cannot be any such thing as a demand, without anyone making it. There cannot be a requirement, if there is no one making it. So even if we can abstract a content from a demand made by an agent at a certain time, for example that a person, P, ought to give away his money to the poor, there is no way to understand the content of this demand, this requirement, to the effect that $\mathrm{P}$ ought to give away his money to the poor, in the absence of someone demanding of him that he do give away his money to the poor.

This move would work against a person who claims that the content of imperatives such as 'Shut the door!' could exist in the absence of anyone issuing them. Imperatives are not truth-apt. But norms are different. Norms are truth-apt. We can identify norms with reference to their truth-conditions.

Suppose I perform a token of the speech-act to describe something. This individual and concrete act of mine, taking place at a particular time, has an abstract content, a proposition. We can assess the truth of the proposition in abstraction from the concrete act of asserting it. As a matter of fact, there are true propositions that no one has ever thought of, let alone asserted. In a similar vein, if I perform a token of the speech act to require something, this individual and concrete act of mine has an abstract content, a proposition (to the effect that something is required). This abstract requirement has truth-conditions. The moral nihilist can argue that these truth-conditions are never satisfied. That is what Mackie wants to show. But it is hard to see how the moral nihilist could convince us that we cannot understand them in the abstract. The assumption that we cannot understand them cannot work as a premise in an argument in defence of moral nihilism.

If moral (normative) non-naturalistic realism is true then there are, objectively existing, demands, in the form of true normative propositions, or, to put it in terms of facts, there are normative facts obtaining, to the effect that we ought to do so and so. Or, to put it in an ontologically speaking even more parsimonious manner, there are things we ought to do.

The claim is not that it is obvious that there are such facts. The claim is merely that it is comprehensible that there are such facts. We need not invoke any ideas of anyone urging us to comply with the relevant norms to understand them. There is nothing queer with normative facts or requirements as such.

\section{A turn to reasons}

As I indicated, Garner's argument has been accepted and repeated by many, but in these days it is often stated differently, namely in terms of moral reasons rather than in terms of norms or demands. Here is one example from Olson: 
The kind of objective prescriptivity Mackie did object to is one that involves categorical reasons. ${ }^{10}$

The stress on 'categorical' is there to indicate that these reasons are genuine ones; they are not 'technical' in nature or of what R. M. Hare used to call values in inverted commas $^{11}$ (i.e. they are not hidden empirical claims cast in normative terminology like, for example: 'if you want to cut that tree you ought to purchase an axe'). The latter kind of 'norms' may be seen as elliptical empirical statements with no satisfaction values at all, to the mere effect that you won't be able to cut the tree unless you purchase an axe. Incidentally, I think 'categorical' a misnomer here, since even hypothetical norms can be genuine norms, such as: 'if an action does not maximise the sum-total of happiness in the universe, it is wrong'. However, what makes this count as a genuine norm is, I suppose, the fact that from it, together a non-moral proposition ('This action does not maximise the sum-total of happiness in the universe') we can derive a categorical norm: 'This action is wrong'. Let us keep this in mind when I continue my argument. The focus here is on genuine and objective prescriptions, not on technical norms. Or, to put it in terms of reasons, the focus is on genuine reasons, not on technical ones.

According to some authors, to have a (conclusive) reason to perform an action, or, having most reasons to perform it, amounts to no more, and no less, than to having a genuine obligation to perform it; Parfit adopts this stance in (Parfit 2011). If this how Olson is using the word 'reason', then, in the quoted passage, we just meet with Garner's objection put in other words. I have then answered it. But other philosophers have taken the notion of a genuine moral reason to constitute a moral explanation of why we ought to perform the action in question; this is the view defended by Tännsjö (2010) and by Broome (2004). On my understanding, this explanation of the obligation will refer to various non-moral facts, and a moral principle, together making the moral fact obtain. On Broome's understanding, the notion of an explanation is taken as primitive. Still, also according to him, a nonmoral fact makes something a normative fact.

If this is how Olson understands the notion of a categorical reason, then one may wonder how non-normative facts can make actions right or wrong. We here meet with an entirely different objection from queerness, of course. When Olson claims that 'moral facts entail facts about categorical reasons and moral claims entail claims about categorical reasons', ${ }^{12}$ he (in the latter of these two claims) speaks of something Mackie did indeed find queer, to wit, the fact that a moral fact is supposed to obtain 'because' a non-moral fact obtains. Mackie had also an argument to the effect that the very notion of moral facts supervening on, or being consequential upon, non-moral ones, was queer. In Mackie's own words:

Another way of bringing out this queerness is to ask, about anything that is supposed to have some objective moral quality, how this is linked with its natural features... The wrongness must somehow be 'consequential' or

\footnotetext{
${ }^{10}$ Olson (2011, p. 64).

11 See for example Hare (1952, p. 164).

12 Ibid.
} 
'supervenient'; it is wrong because it is a piece of deliberate cruelty. But just what in the world is signified by this 'because' ${ }^{13}$

This is a different argument from queerness, however, and it has nothing to do with prescriptivity as such; I have discussed it elsewhere, ${ }^{14}$ and will say no more about it in the present context.

\section{Yet another argument from queerness?}

Finally, could Mackie not be taken to argue, simply, that objective prescriptions are queer because they constitute a superfluous (not necessary) addition to our 'ordinary' empiricist ontology? So, even if prescriptivity is not queer as such, objective prescriptivity is queer-for this simple reason.

Something Mackie writes about 'companions in guilt' does indeed suggest such a reading of his argument. What if there are other entities, such as our ideas about essence, number, identity, diversity and so forth, some of which may resist our attempts to construct, on empiricist foundations, an account of them, he asks himself, and gives the following answer:

If some supposed metaphysical necessities or essences resist such treatment, then they too should be included, along with objective values, among the targets of the argument from queerness. ${ }^{15}$

One way of understanding him is as I have just indicated. This, however, strikes me as an extremely dull interpretation. His argument from queerness, on this understanding of him, collapses into this single one: entities we cannot account for in empiricist terms are not real (or should not be taken to be real). The only function of the word 'queer' then is rhetorical.

But another and more charitable interpretation of the quoted passage is also possible. One could speak of it as the challenge interpretation. According to the challenge interpretation, if there are necessities or essences, that do not form part of our empiricist understanding of the universe, then Mackie takes upon himself to find some peculiar aspects of each and any one of them in which they are queer, apart from being additions to our empiricist understanding of the universe-in the manner he claims to have done with moral properties.

\section{Conclusion}

Mackie has not, in the part of his argument from queerness with which I have here been engaged, ${ }^{16}$ been able to show that categorical (genuine) norms or categorical

\footnotetext{
13 Ibid. (p. 41).

14 Tännsjö (2010).

15 Mackie (1977, p. 39).

16 I have said nothing to answer the epistemic aspect of his argument from queerness, to the effect that, even if objective prescriptive properties existed, we would not be able to gain knowledge of them. This is his most serious challenge to the moral realist. I discuss and try to answer it in Tännsjö (2010).
} 
normative claims are so queer that they cannot form part of the fabric of the universe. If there is such a thing as objectively existing prescriptivity, as the moral realist claims, then we can also explain why_and we need not deny that-strong (conceptual) internalism is true. Strong conceptual internalism is true, not because of any magnetic force thought to be inherent in moral properties themselves, but because we do not allow that anyone has (in the practical sense) 'accepted' a normative claim, unless she is prepared to some extent to act on it (to see to it that its satisfaction-conditions are actually met).

Acknowledgments I thank Jens Johansson, Victor Moberger, Jonas Olson, and an anonymous reviewer for the journal, as well as the joint Uppsala/Stockholm Higher Seminar in Practical Philosophy for valuable comments on earlier drafts of this paper.

\section{References}

Björklund, F., Björnsson, G., Eriksson, J., Francén Olinder, R., \& Strandberg, C. (2011). Recent work: Motivational internalism. Analysis, 72, 124-137.

Broome, J. (2004). Reasons. In J. Wallace, M. Smith, S. Scheffler, \& P. Pettit (Eds.), Reason and value: Themes from the moral philosophy of Joseph Raz (pp. 28-55). Oxford: Oxford University Press.

Copp, D. (2009). Realist-expressivism and conventional implicature. In R. Shafer-Landau (Ed.), Oxford studies in metaethics (Vol. 4, pp. 167-202). Oxford: Oxford University Press.

Dreier, J. (2010). Mackie's realism: Queer pigs and the web of belief. In R. Joyce \& S. Kirchin (Eds.), A world without values (pp. 71-86). Leiden: Springer.

Garner, R. T. (1990). On the genuine queerness of moral properties and facts. Australasian Journal of Philosophy, 68, 137-146.

Hare, R. M. (1952). The language of morals. Oxford: Oxford University Press.

Mackie, J. L. (1977). Ethics: Inventing right and wrong. New York: Penguin books.

Olson, J. (2011). In defence of moral error theory. In M. Brady (Ed.), New waves in metaethics (pp. 62-84). Basingstoke: Palgrave Macmillan.

Parfit, D. (2011). On what matters. Oxford: Oxford University Press.

Tännsjö, T. (2007). Moral relativism. Philosophical Studies, 135, 123-143.

Tännsjö, T. (2010). From reasons to norms. On the basic question in ethics. Dordrecht: Springer.

Tresan, J. (2006). De dicto internalist cognitivism. Noûs, 40, 143-165.

Tresan, J. (2009). Metaethical internalism: another neglected distinction. Journal of Ethics, 13, 51-72. 